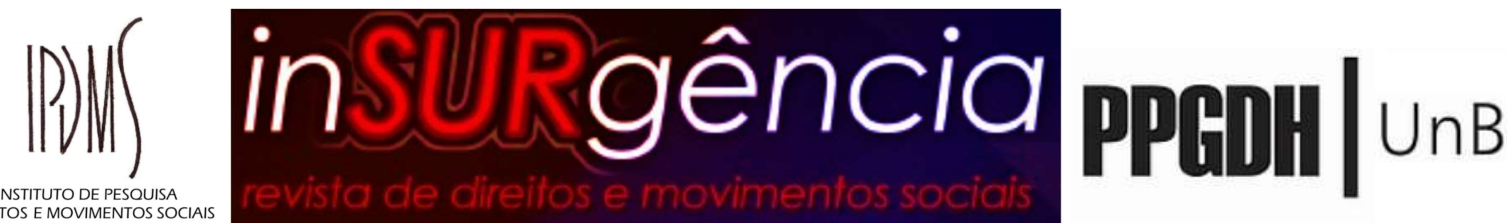 \\ DIÁLOGOS INSURGENTES
}

Seção de entrevistas 


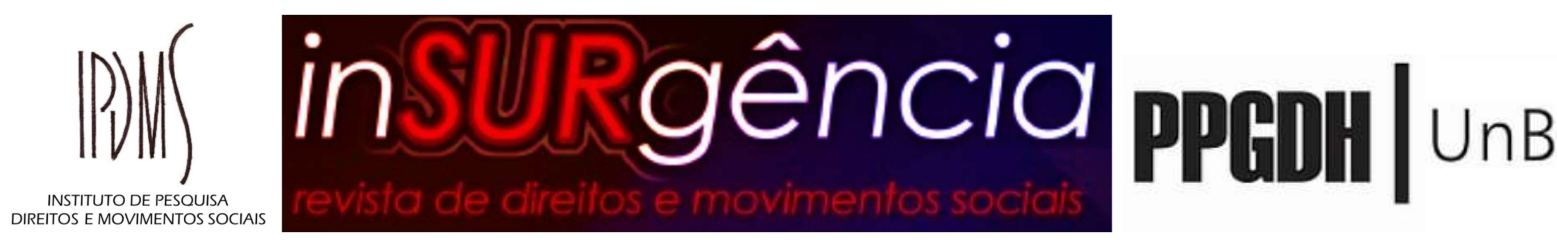

\section{Entrevista de Karina Macedo Fernandes ${ }^{1}$, concedida a Pedro Bigolin Neto ${ }^{2}$, organizador do volume $6, n^{0} 1$, da revista InSURgencia.}

\section{Rodrigo de Medeiros Silva: O direito à propriedade é um direito humano e uma das bases do direito civil. No entanto, seu conceito e seus objetivos passaram por transformações substanciais nas últimas décadas como, por exemplo, pelo advento de sua função social. Quais os fatores que levaram a esta mudança de compreensão?}

Karina Macedo Fernandes: O direito de propriedade surge como forma de proteção dos bens e garantias individuais em relação à ação estatal, tendo em vista que a propriedade privada é um dos pilares da civilização ocidental. Assim, a propriedade é o direito que a pessoa física ou jurídica tem de usar, gozar, dispor de um bem ou reavê-lo de quem injustamente o possua ou detenha. A constituição do instituto da propriedade e sua localização histórica inicia com o direito romano, com a propriedade coletiva, que posteriormente se transformaria em propriedade individual. Seu pressuposto era a distribuição a partir do quanto cada tribo ou família poderia produzir, ou seja, a distribuição de terras dependia das condições e possibilidades do respectivo trabalho. Sucessivamente, a preocupação do Império Romano com a distribuição de terras levou às lutas sociais pela propriedade, com os movimentos dos plebeus contra o enriquecimento dos patrícios, o que demonstra a associação da propriedade aos interesses políticos, sociais e econômicos de cada época. Com isso, a tradição do conceito de propriedade em Roma é de um direito individual, absoluto e perpétuo, ilimitado sob qualquer perspectiva.

Muito embora o conceito de propriedade se mantenha conforme suas raízes romanas, o caráter absoluto da propriedade passou a ser questionado na modernidade, conforme as

\footnotetext{
${ }^{1}$ Doutora (2019) e mestra (2014) em Direito Público pela Universidade do Vale do Rio dos Sinos - UNISINOS. Graduada em Direito pela Universidade Federal do Rio Grande - FURG (2012). Integrante do Núcleo de Direitos Humanos da UNISINOS. Desenvolve pesquisas na área de Direito, com ênfase em direitos humanos, direito à cidade e pensamento descolonial.

${ }^{2}$ Mestre em Direito Público pela Universidade do Vale do Rio dos Sinos - UNISINOS (2017). Graduado em Direito pela Pontifícia Universidade Católica do Rio Grande do Sul - PUCRS (2014). Pesquisador do Centro de Direitos Humanos e Empresas da Fundação Getúlio Vargas (FGV). Assistente de Pesquisa da School of Public Policy and Administration - SPPA - da Carleton University. Pesquisador do Núcleo de Direitos Humanos (NDH) da UNISINOS. Tem interesse nas Ciências Jurídicas e Sociais, intrinsecamente interdisciplinares, com ênfase nos Direitos Humanos, no Direito Ambiental, no Direito Constitucional e no Direito Internacional, e também nos demais conhecimentos que atravessam estas áreas, como Antropologia, Ciência Política, Sociologia, Filosofia, Psicologia, Ecologia, Teoria Crítica e Estudos Decoloniais.
} 


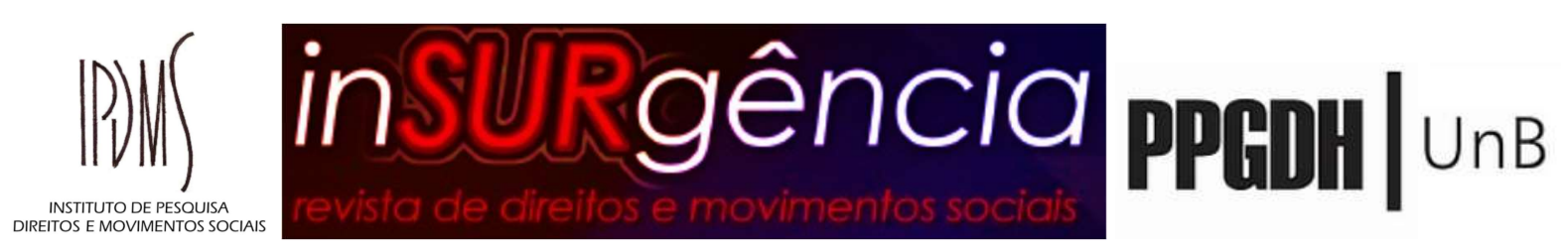

declarações de direitos advindas da Revolução Francesa e do movimento de independência dos Estados Unidos. Nesse período, a propriedade passou a ser considerada um direito absoluto desde que exercido em consonância com os ordenamentos jurídicos de cada Estado. Operouse, a partir da propriedade, um enfrentamento ao absolutismo do Estado, ao tornar o direito de propriedade uma garantia fundamental a qualquer indivíduo, limitando, assim, a ação do Estado.

De acordo com a teoria liberal-contratualista, sobretudo para Hobbes e Rousseau, os dois preceitos fundamentais da constituição do Estado são a justiça e a propriedade, de maneira que o soberano vincula ao sujeito a propriedade e a atribui a determinado súdito em detrimento de outrem, assegurando, assim, a paz e a justiça social (Hobbes), assim como o contrato social é visto como o resultado do encontro entre as vontades subjetivas individuais e concretas dos contratantes, considerando o indivíduo como um ser racional que coexistia racionalmente em sociedade (Rousseau). A propriedade é, assim, vista como a base da constituição do Estado e da constituição do sujeito, uma vez que a dimensão imaterial, subjetiva, da propriedade constitui a base das sociedades livres.

Nesse sentido, Hegel é quem explica a propriedade como o eixo fundamental que liga a pessoa, a liberdade e o contrato. Para Hegel, a liberdade é o exercício da propriedade como exercício da vontade abstrata em geral, enquanto as pessoas se relacionam como proprietárias por força do contrato. No aspecto material, a vontade individual é a propriedade privada em si mesma, uma vez que é a partir da vontade, em conluio com a representação e a personalidade, que a coisa passa a ser objeto da tomada da posse que concretiza a propriedade material.

A posse é, portanto, o vínculo entre a propriedade e a pessoa, o centro do qual partem todas as disposições jurídicas e políticas no corpo social para a filosofia hegeliana. A síntese do Estado político é, por excelência, a síntese da propriedade fundiária e da vida familiar, concepção que Karl Marx critica em "Crítica da filosofia do direito de Hegel”, ao fazer uma releitura do conceito estamental de sociedade civil, que Hegel constrói a partir da correlação dos proprietários fundiários.

É na leitura do contrato de propriedade enquanto símbolo do nascimento do sujeito que reside o ponto de partida para uma leitura crítica da propriedade privada como a realizada por Marx, para quem a propriedade deve ser coletiva, deve atingir um fim social. A propriedade, na crítica marxiana, está localizada entre o capital e o trabalho: nas sociedades capitalistas, o capital é um poder pessoal, que existe mediante a força de trabalho do proletariado. Nesse 


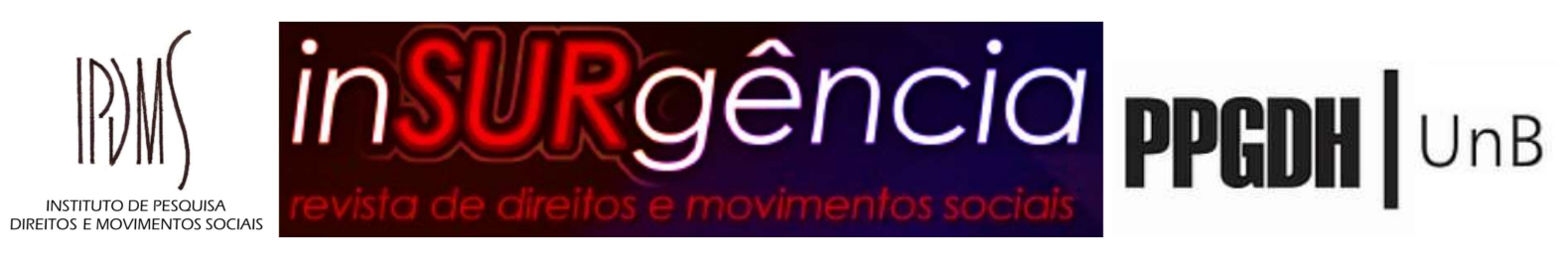

sentido, a propriedade privada é a transformação do capital individual, pertencente ao monopólio proprietários dos meios de produção.

É na atribuição de uma função social à propriedade que se iniciam as limitações a este direito, da mesma forma que seu valor jurídico passa a ser considerado. A relação entre propriedade e sujeito torna o direito de propriedade um bem jurídico caro à pessoa humana. Muito embora não seja um direito imprescindível à vida digna, o direito de propriedade é o direito de realização econômica, social e cultural da pessoa. A relativização do direito de propriedade remanesce às condições de realização dos direitos humanos, o que significa dizer que é preciso o reconhecimento das condições necessárias para que os direitos humanos sejam realizados. Nesse sentido, o reconhecimento do caráter social dos direitos humanos é o que viabiliza a consideração dos direitos econômicos, sociais e culturais como parte constitutiva do conceito de direitos humanos segundo a Declaração de Viena de 1993.

No Brasil, o direito à propriedade está garantido no artigo $5^{\circ}$, XXIII, da Constituição Federal, e nos artigos 524 a 648 do Código Civil. Sua função social adveio no artigo $5^{\circ}$, XXIII da Constituição Federal e no artigo 421 do Código Civil, e é possível dizer que a atribuição de uma função social a um dos direitos mais expressivos do nosso ordenamento jurídico corresponde à constitucionalização do direito civil. Isso significa dizer que o texto constitucional prepondera sobre todo o ordenamento jurídico e que tanto os fundamentos quanto os objetivos da República Federativa do Brasil, expressos nos artigos primeiro e terceiro da Constituição, prevalecem sobre todos os direitos.

Entretanto, o que vemos na prática é que o direito de propriedade é predominante na sociedade capitalista e nem mesmo a sua relativização normativa - através da função social tem a capacidade de enfraquecer sua predominância sobre os demais direitos. O Estado, para defender seu sistema de direitos no qual predomina o direito à propriedade, utiliza-se do seu monopólio sobre o uso legítimo da violência e, com isso, exercita seu poder de monopólio sobre o dinheiro a moeda corrente, produtos da construção do valor de troca ancorado na propriedade individual privada.

RMS: A luta pelos direitos humanos à cidade e à moradia tem tomado crescente visibilidade e integrado a pauta de diversos movimentos sociais ao redor do globo. Com base em suas pesquisas, a atual configuração do espaço urbano das grandes metrópoles, 


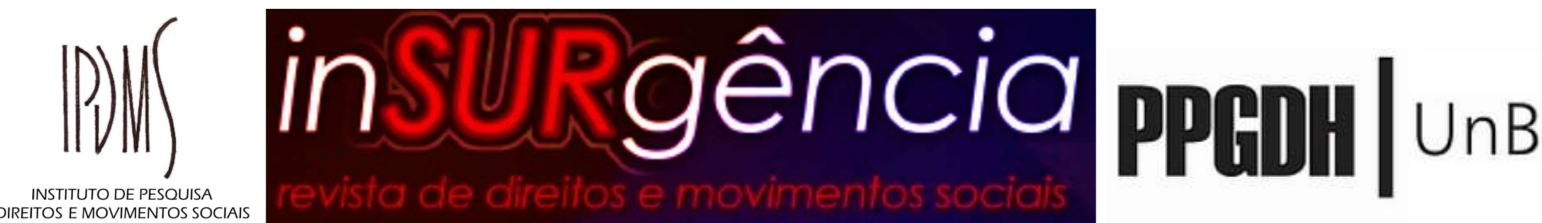

com seus igualmente grandes eventos e projetos imobiliários, revela-nos este fenômeno a partir de onde?

KMF: É importante situar esses direitos e as lutas sociais que os prescindem no contexto atual, de aumento significativo de despejos e deslocamentos compulsórios nas grandes cidades, somado às crises do capitalismo financeiro pós-colapso do sistema financeiro globalizado de 2008. Isso tudo se reflete diretamente na produção do espaço urbano constituído, especialmente na moradia, e nos coloca diante da construção de uma hegemonia ideológica e prática de um modelo de urbanização sem planejamento territorial, no qual a habitação se transforma em ativo financeiro. Nesse contexto, a propriedade individual clássica e escriturada desponta como um dos meios mais poderosos de exclusão social e territorial. Os territórios acabam se reduzindo a espaços estritos de valor econômico e de perspectivas de rendimentos futuros, motivo pelo qual a perpetuação da propriedade se torna uma condição de sobrevivência no mundo dos contratos e das finanças.

Diante do crescimento da propriedade e da habitação como fronteiras de expansão do capital financeiro, o planejamento territorial urbano se mostra imprescindível à constituição de cidades que se pretendem inseridas em um Estado Democrático de Direito, como ocorre no Brasil. Ao contrário disso, o fortalecimento do complexo imobiliário-financeiro tem como principal impacto a despossessão massiva de territórios, o empobrecimento substancial da população - desde a criação da categoria de pobres urbanos "sem lugar" até os processos de subjetivação estruturados a partir da lógica capital do endividamento - e a segregação social cada vez mais profunda das cidades. No cenário brasileiro, verifica-se um padrão colonial de cidade a partir do que Raquel Rolnik denomina de colonização dos lugares.

Nesse cenário, as possibilidades de concretização da regularização fundiária no Brasil têm se verificado no direito urbanístico, tanto pela via judicial quanto pela via administrativa. Consequentemente, emergem como principais entraves à via pública de regularização fundiária a fragilidade da esfera local, na gestão de processos complexos e conflitivos, pela descontinuidade administrativa, através de pactos locais eleitorais que dificultam o manejo do aparato legal protetivo de direitos coletivos contra segmentos sociais empoderados e patrimonializados, além do desaparelhamento teórico, político e material de órgãos como a Defensoria Pública, órgãos urbanísticos locais e dos movimentos sociais. 


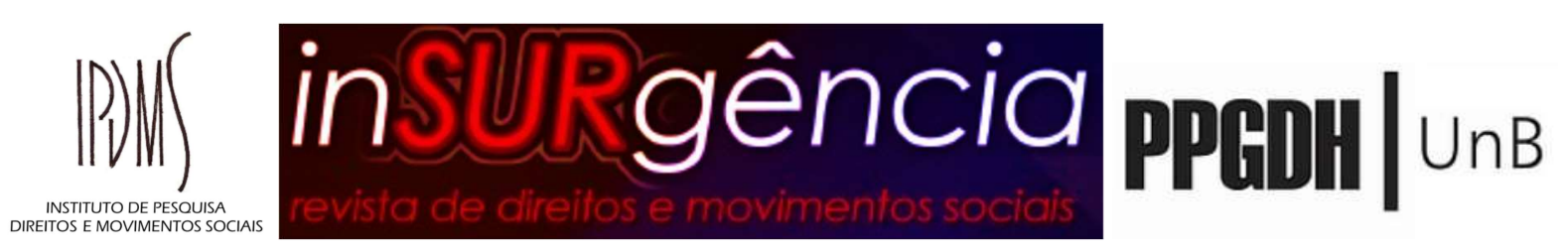

Sobretudo, devemos considerar que a ausência de infraestrutura básica (saneamento, atendimento à saúde, segurança e educação) em diversos espaços da cidade, a ausência de controle sobre os preços do aluguel, a especulação imobiliária e a exposição de diversas regiões a riscos ambientais, como de deslizamentos e enchentes, é diretamente associada ao déficit de moradia e de cidade, e compõe um contexto de vulnerabilidade generalizado que exige a formação de um programa público que atenda as pessoas atingidas nesse contexto. As ocupações de áreas urbanas surgem para preencher esta ausência do Estado e costumam ocorrer em prédios vazios e subutilizados, bem localizados nas cidades, que já foram moradia ou espaços comerciais. Esses locais, que não estão habilitados para produzir moradia, acabam constituindo vazios urbanos e servindo ao capital especulativo, à margem do Estado.

Da mesma forma, há muitos territórios populares nas cidades que foram autoconstruídos e que têm condições de serem habilitados para moradia, mas em que o Estado não chega para cumprir seu dever. Nesses lugares, as ocupações assumem o papel do Estado e realizam política urbanística para as pessoas que vivem ali, garantindo moradia, acesso à cidade, à saúde, à educação, ao saneamento básico, à cidadania e à cultura conforme assegurado pela Constituição Federal da República Federativa do Brasil de 1988 e por tratados dos quais o Estado brasileiro é signatário, como o Pacto de San Salvador.

RMS: Partindo destas considerações acerca dos direitos humanos à propriedade, à cidade e à moradia, a senhora poderia comentar sobre as respostas oferecidas pelo Poder Judiciário no âmbito do direito civil e processual civil?

KMF: É possível afirmar que o Estado deixa de cumprir a Constituição Federal na garantia dos direitos à moradia e à cidade ao ceder à pressão da especulação imobiliária em detrimento de pessoas em vulnerabilidade social, por exemplo. Quando uma ação de reintegração de posse ajuizada por um Município é julgada procedente sem que haja demonstração cabal pelo Município acerca do motivo que o leva à retomada de imóvel ocupado por um munícipe e que tampouco haja demonstração de uma destinação adequada àquela pessoa que necessita do Estado para sobreviver, ocorre uma falha do Estado. Estes casos são comuns no Poder Judiciário, sobretudo na região sudeste do Brasil, e retratam a situação dos direitos sociais diante da institucionalidade. 


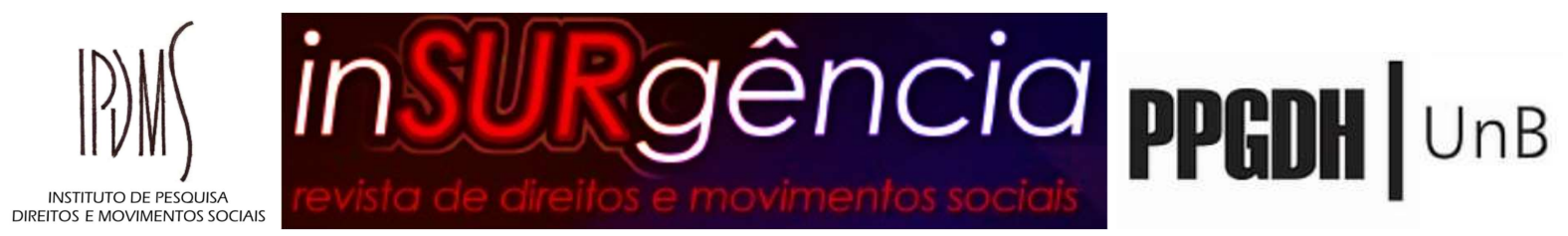

Muito comuns são os casos em que a falta de titulação da propriedade ocupada constitui o único motivo que desqualifica a posse exercida e caracteriza turbação ou esbulho da posse indireta do proprietário. Outros fatores que deveriam ser levados em conta, sobretudo em razão da função social da propriedade e do direito à moradia, são muitas vezes relegados diante da falta de regularização fundiária. Esta mesma ausência de regularização fundiária é utilizada como justificativa pelo Poder Público, tanto no Executivo quanto no Judiciário, para discriminar moradores de ocupações urbanas e atribuí-los o status de cidadãos de segunda classe, para quem não são destinados os serviços públicos básicos, como saneamento básico, energia elétrica, assistência social, devido processo legal, entre outros.

Sabemos, entretanto, que há um déficit habitacional cada vez mais gigantesco no Brasil (mais de seis milhões de moradias) e que o Estado deixa de agir ao não garantir a dignidade dos moradores de uma ocupação urbana em um caso de despejo, ao não habilitar as forças de segurança pública para agir dentro dos limites da dignidade da pessoa humana. Quando o Estado deixa de garantir políticas sociais de moradia ou reassentamentos dignos para as pessoas diretamente atingidas pelo déficit habitacional, também se verifica essa ausência dilaceradora.

O caso da reintegração de posse da Ocupação Lanceiros Negros, em Porto Alegre, é um exemplo perfeito de como o Estado brasileiro negligencia a proteção da vida e da integridade física de pessoas ocupantes sem título de propriedade. A Ocupação se instalou em um prédio público, onde funcionou antiga sede do Ministério Público Estadual, e lá permaneceu por aproximadamente três anos, conferindo a função social ao bem público que estava abandonado há aproximadamente dez anos, até que ocorreu o despejo dos ocupantes no âmbito da ação de reintegração de posse ajuizada pelo Estado do Rio Grande do Sul. A violência empregada pela Brigada Militar na realização do despejo, o horário em que realizado por determinação judicial (à noite, após o horário comercial), bem como o intenso frio ocorrido durante o despejo $\left(10^{\circ} \mathrm{C}\right)$ e nos dias que o sucederam evidenciaram a vulnerabilidade das famílias ocupantes e o despreparo dos agentes públicos para lidar com questões complexas como remoções de pessoas dentro da cidade.

Este foi um caso emblemático em que se expôs o paradigma da questão urbana brasileira frente ao déficit habitacional e as ocupações de prédios e áreas públicas e privadas por movimentos de luta por moradia. Percebe-se a necessidade de se difundirem informações sobre a legitimidade das ocupações urbanas, tanto no plano político quanto no plano jurídico, tendo em vista que o direito à propriedade, embora constitua a proteção jurídica mais antiga 


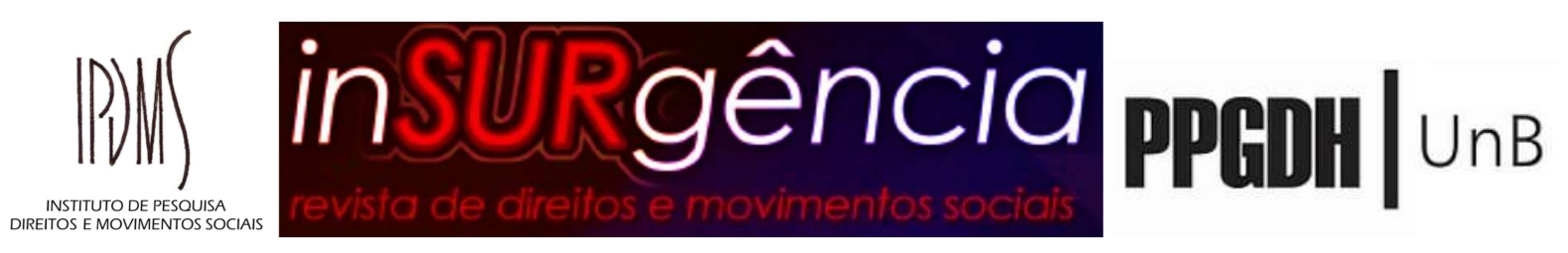

que se tem conhecimento, não se trata de uma garantia absoluta nos termos da Constituição Federal.

Uma possibilidade de se enfrentar, quiçá superar, este contexto grave e urgente está na busca de outros meios de mediação em que se consubstancie uma perspectiva de direitos humanos, como também ocorre em alguns casos levados ao Poder Judiciário. Há decisões de Juízes e Desembargadores que regulam os despejos, estabelecendo limites ao cumprimento de uma ordem de despejo, e até mesmo, é importante dizer, há certa regulação de diretrizes básicas nesse sentido. No Poder Judiciário do Rio Grande do Sul, já existe um Protocolo Interinstitucional para Cumprimento dos Mandados de Reintegração de Posse em Conflitos Urbanos Coletivos, o que nos revela uma preocupação em dar cumprimento ao Pacto dos Direitos Econômicos, Sociais e Culturais, do qual o Brasil é signatário, e ao Comentário Geral da ONU n ${ }^{\circ}$. 7, que contempla garantias e diretrizes nas desocupações forçadas, de maneira a evitar graves violações de direitos humanos. Há também o acórdão do processo $\mathrm{n}^{\mathrm{o}}$. 8.2019.5661/000003-6, no qual a Comissão de Direitos Humanos do Tribunal de Justiça expressa uma preocupação com a situação das famílias que vivem em ocupações urbanas, recomendando a adoção de medidas que possam minimizar eventuais conflitos que possam resultar em violência e ofensa à integridade física e psíquica de ocupantes e de responsáveis pela desocupação das áreas ocupadas, orientando Magistrados para que fomentem a cultura da mediação e da conciliação no Poder Judiciário, determinando a expedição de ofício-circular orientando e recomendando aos Magistrados que observem o Protocolo Interinstitucional para Cumprimento dos Mandados de Reintegração de Posse em Conflitos Urbanos Coletivos, e determinando a implementação de curso de aperfeiçoamento de Magistrados nas áreas de Direito Urbanístico e Direitos Humanos, com ênfase em mediação nas ações de despejo coletivo e de reintegração de posse. Ambas as ações são de 2019 e se instauraram a partir de reuniões e conversas entre o Poder Judiciário e o Conselho Estadual de Direitos Humanos do Rio Grande do Sul.

\section{RMS: Neste sentido, quais os potenciais da judicialização enquanto ferramenta de efetivação dos direitos humanos aqui abordados?}

KMF: Como disse, é importante a concretização de uma cultura de mediação no âmbito do Poder Judiciário, que possa dar sentido às ocupações e aos despejos cotidianamente enfrentados 


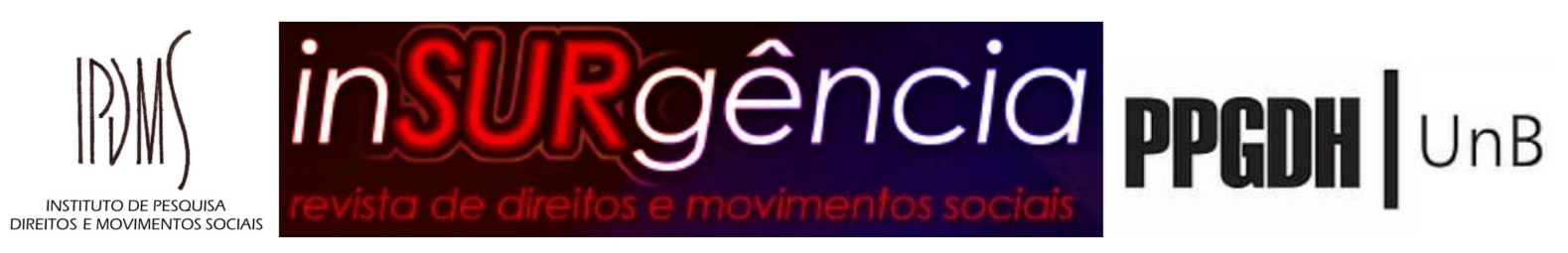

no Brasil. A determinação judicial de um despejo cria um problema maior porque as pessoas não desaparecem ao serem despejadas. Permanecem, na verdade, sem moradia e sem amparo estatal, o que certamente as levará a ocupar outra área que não cumpra função social, o que geralmente ocorre em áreas de preservação ambiental. Disso se conclui que a judicialização é importante, mas, sozinha, não enfrenta o problema da moradia e da cidade.

Ultimamente, tenho acompanhado casos em que se exige a aplicação da Lei $n^{\circ}$. 13.465/17, a Lei da Regularização Fundiária, também conhecida como Reurb, para a regularização de grandes ocupações. Tendo em vista que o Estado tem o dever de aliviar as tensões inerentes às ocupações urbanas e auxiliar na composição de todos os interesses envolvidos, cabe a ele, especialmente diante da Lei da Regularização Fundiária, identificar núcleos urbanos informais, criar unidades imobiliárias compatíveis com o planejamento urbano, priorizar a permanência dos ocupantes no local, prevenir a formação de novos núcleos urbanos informais, conceder direitos reais, e possibilitar a participação dos interessados nas etapas da regularização fundiária. Com a Reurb, a remoção das famílias passa a ser o último caso a ser considerado perante instrumentos jurídicos que podem ser destinados à consolidação da regularização fundiária nos termos da Lei, o que explica que o papel do Estado exige uma postura ativa que regularize as ocupações urbanas da melhor forma possível aos ocupantes.

Ao Poder Judiciário, cabe decidir nos termos da Constituição quanto à função social da propriedade e o direito à moradia, e nos termos da lei, especialmente do Estatuto da Cidade, que estabelece o direito à cidade e à moradia, a gestão democrática da cidade e a função social da cidade e da propriedade como os três princípios elementares da política urbana. Para que isso se estabeleça, é sobremaneira essencial que se veja a cidade como um espaço de usufruto coletivo e não de disputa social e de circulação do capital, motivo pelo qual vejo ações como as do Poder Judiciário gaúcho com potencial de mudanças positivas no resgate desse sentido de cidade que é diariamente forjado para servir aos interesses do capitalismo.

\section{RMS: Por fim, há algo que a senhora deseja acrescentar que não lhe foi perguntado?}

KMF: É importante ter em vista o contexto geopolítico em que se insere a urbanização brasileira. A cidade latino-americana nasce colonial e a colonialidade está presente em todos os momentos históricos, sociais, econômicos e políticos de sua constituição, até a atualidade. O imaginário colonial reside na ideia de que a civilização e a superioridade estariam somente nas 


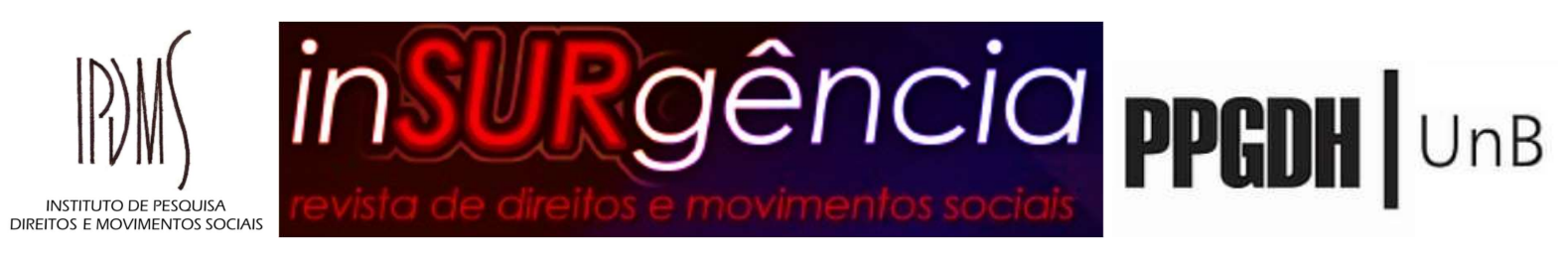

cidades, o que as tornou centro de referência de poder e dominação, o centro da noção de civilização e de superioridade, em oposição ao rural, ao indígena, ao atrasado.

É por isso que as cidades, destinadas às classes mais privilegiadas e que se beneficiam com o capitalismo dependente, são pensadas e planejadas para priorizar o enriquecimento e a elevação da qualidade de vida desta burguesia em detrimento daqueles que estão à margem do processo produtivo da sociedade capitalista. No processo de reorganização do espaço urbano, o direito à cidade é negligenciado a milhares de pessoas que, embora construam o espaço urbano, têm sua circulação nele cada vez mais restrita. A segregação entre aqueles que podem pagar pelo acesso à cidade e aqueles que não têm condições de participar da urbanização hegemônica é intensificada com a difusão de um modelo de "planejamento estratégico" cujo objetivo é a promoção da cidade enquanto uma mercadoria de luxo e com acesso restrito.

Nesse sentido, a exclusão urbanística se dá no âmago da ambiguidade jurídica que caracteriza as diversas formas de ocupação da cidade, um conjunto de "territórios de definições cambiantes entre legal e ilegal, construídos a partir de pressões, mediações políticas e camadas de legalidades", como afirma Raquel Rolnik no seu "Guerra dos Lugares" (2015, p. 173). Com isso, afirmamos que a produção do espaço urbano é marcada por um planejamento urbano seletivo que estimula a informalidade e a ilegalidade. A ambiguidade que constitui a política e regulação urbanística e determina zonas de fronteira entre o legal e o ilegal, entre o público e o privado, entre o formal e o informal, é direcionada e propositada à segregação. Sobre a autoconstrução de territórios populares, o Estado se situa numa zona de indefinição: não investe em infraestrutura urbana nesses territórios, que, assim como seus constituintes, estão à margem da lei; esta pode ser utilizada, na verdade, para expulsar os moradores ilegais dos territórios ilegais. Por outro lado, à produção do enobrecimento urbano, por meio de empreendimentos de luxo e revitalizações de áreas históricas, o Estado é flexível na medida em que oportuniza a defesa da propriedade como prioridade elementar. A ambiguidade da ordem jurídicourbanística é funcional e estabelecida sobre relações políticas arcaicas, voltadas a um mercado imobiliário restrito e especulativo e assente na aplicação da lei conforme os interesses políticos e econômicos.

Considerando a produção do espaço urbano decisiva para a acumulação do capital, e que as forças necessárias à circulação do capital são predominantes no planejamento urbano, é necessário entender como lidar com essa lógica política e ideológica que, para atender seus 


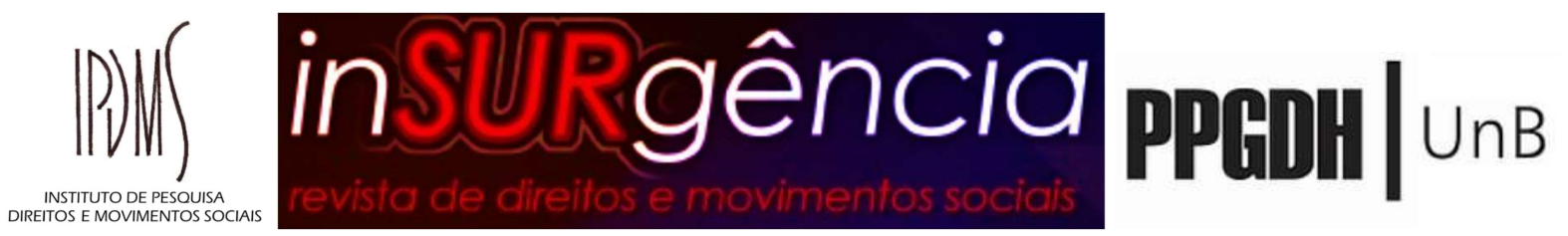

fins em conformação com os interesses do capital e das elites dominantes, opera mecanismos de controle e de dominação a partir do poder político, da burocracia estatal e da legislação. Eu vejo os movimentos sociais e a sociedade civil organizada como atores fundamentais nessa compreensão, que passa por uma abordagem propositiva de um novo sentido para a ideia de cidade que desconstrua a abstração ideológica e especulativa que produz a cidade desigual. A luta pelo direito à moradia e pelo direito à cidade é construída desde abajo e suas condições de possibilidade necessariamente passam pela organização política perante o capital, o Estado e a institucionalidade. 